\title{
Lacan Leitor de Melanie Klein: O Caso Dick em Questão ${ }^{1}$
}

\author{
Ariana Lucero ${ }^{2}$ \\ Universidade Federal do Espirito Santo \\ Angela Maria Resende Vorcaro \\ Universidade Federal de Minas Gerais
}

\begin{abstract}
RESUMO - O artigo apresenta a leitura que Jacques Lacan faz do caso Dick, de Melanie Klein. Para tanto, a discussão com o filósofo Jean Hyppolite é retomada com o objetivo de explicitarmos como os mecanismos de Ausstossung [expulsão], Verneinung [negação] e Bejahung [afirmação], descritos por Freud em 1925, podem contribuir para a compreensão da constituição psíquica sob uma perspectiva lacaniana. Em seguida, expomos o caso, tanto para apreendermos clinicamente o que foi exposto na teoria, quanto para evidenciarmos como Lacan se distancia da concepção de fantasia de M. Klein. O tema do diagnóstico, no entanto, aparece em ambos ligado a uma forma de organização subjetiva ainda em constituição na infância, o que traz elementos para refletirmos sobre essa questão na atualidade.
\end{abstract}

Palavras-chave: Lacan, Jacques-Marie Émile, 1901-1981, Klein, Melanie, 1882-1960, constituição psíquica, linguagem, diagnóstico

\section{Lacan Reads Melanie Klein: Thoughts on the Case Dick}

\begin{abstract}
This article presents Jacques Lacan's reading of Melanie Klein's case Dick. In order to do so, one revisits the debate with the philosopher Jean Hyppolite to explicitate how the mechanisms of Ausstossung [expulsion], Verneinung [denial] and Bejahung [affirmation], described by Freud in 1925, may contribute to the understanding of mental constitution under a Lacanian perspective. Next, one brings the case to light to apprehend what was presented in theory from a clinical standpoint as well as to evidence how Lacan distances himself from Klein's conception of fantasy. The subject of diagnosis, however, appears in both authors related to a form of subjective organization in a constitution which provides elements to reflect on this issue in contemporaneity.
\end{abstract}

Keywords: Lacan, Jacques-Marie, Klein, Melanie, mental constitution, language, diagnosis

Neste artigo, faremos uma exposição da leitura que Jacques Lacan (1901-1981) faz do caso Dick, atendido por Melanie Klein (1882-1960). Para isso, é importante esclarecermos o referencial teórico utilizado pelo psicanalista francês no contexto desta discussão. Em seu Seminário 1: os escritos técnicos de Freud (1953-54), Lacan retoma o caso Dick logo após reler, com o auxílio do filósofo hegeliano Jean Hyppolite (1907-1968), o texto freudiano "A Negação" [Die Verneinung] (1925), com ênfase nos mecanismos de Ausstossung [exclusão], Verneinung [negação] e Bejahung [afirmação], na medida em que, com eles, seria possível abordar como se forma o pensamento, de forma não dissociada da constituição psíquica: afeto e representação, cognição e subjetividade, para a psicanálise, não são campos separados. Assim, depois de elucidar esses conceitos, localizaremos, na clínica psicanalítica kleiniana, elementos que auxiliam a esclarecê-los e a problematizá-los. Retomando considerações lacanianas que versam sobre a função essencial da linguagem, bem como sobre a tripartição da realidade psíquica por meio das categorias do real, do simbólico e do imaginário, analisa-se o que estaria em jogo tanto na análise empreendida por Melanie Klein quanto na

1 Apoio: CAPES/FAPES e CNPq

2 Endereço para correspondência: Rua Constante Sodré, 1234/102, Vitória, ES, Brasil. CEP: 29.055-420.E-mail: luceroariana@yahoo. com.br constituição psíquica. Buscando afastar-se de explicações psicanalíticas calcadas em fantasias infantis supostas, Lacan (1953-54/1979) se detém em operadores clínicos que permitiriam correlacionar manifestações do funcionamento psíquico e determinações estruturais. A problematização do diagnóstico comparece, aqui, ligada à questão das estruturas clínicas de modo pungente quando tratamos da infância. Afinal, em que medida um diagnóstico pode selar o destino de uma criança, fazendo de seu comportamento algo que, simplesmente, corresponde univocamente a uma sintomatologia prevista? Considerando que o diagnóstico de autismo vem sendo definido cada vez mais cedo a partir de catálogos de sinais, os comentários de Klein e de Lacan sobre o diagnóstico na infância podem ser bastante esclarecedores, por focalizarem um tempo da constituição subjetiva que antecede a possibilidade de fixação, por especialistas, de um quadro clínico definitivo. Ao situarem, na criança, a abertura a mudanças e intervenções, os autores nos conduzem a interrogar a precocidade de diagnósticos que, longe de tratar o sofrimento da criança, podem operar como profecias autorrealizáveis.

\section{Ausstossung, Verneinung e Bejahung}

A partir do diálogo estabelecido com Jean Hyppolite no contexto de seu Seminário 1, Lacan (1953-54/1979) nos 
lembra que as explicações sobre o texto $A$ Negação (1925) nos ensinaram que: "a condição para que alguma coisa exista para o sujeito, é que haja Bejahung [afirmação], essa Bejahung que não é negação da negação" (p. 73). Tal atitude de negação é a que podemos ver nos exemplos mobilizados por Freud (1925/2007) no início de seu texto: “'O senhor me pergunta quem poderia ser essa pessoa no meu sonho. Não é a minha mãe'. E nós corrigimos: 'Portanto, é sua mãe'" (p. 147). Essa forma de negação, comum no cotidiano, é lida por Freud (1925/2007), na verdade, como uma afirmação: o sujeito se serve de uma sentença que ele nega para falar de seu próprio desejo por sua mãe, que, de outra forma, não poderia aparecer. Tal possibilidade de se manifestar, de ser, é, então, facultada pelo uso da negação, que é uma forma de o sujeito ter acesso ao conteúdo recalcado através de uma Aufhebung der Verdrängung. Hyppolite (1954/1998) destaca que, na dialética hegeliana, o termo Aufhebung quer dizer, ao mesmo tempo, negar, suprimir e conservar; tratar-se-ia de uma forma de suspensão ou supra-assunção em que o conteúdo a ser ultrapassado seria, de alguma forma, conservado. Estaria em jogo na Verneinung, portanto, uma suspensão do recalque, sem, efetivamente, uma aceitação ou uma negação completa do mesmo (cf. Freud, 1925/2007, p. 148).

Freud (1925/2007, p. 147-148), com efeito, assevera que a negação é uma maneira de se tomar conhecimento do recalcado em um plano apenas intelectual. Dessa forma, o conteúdo outrora reprimido pode chegar à consciência sem que o essencial do recalque, o processo afetivo, seja mobilizado. A negação opera, assim, no domínio das palavras, no intuito de evitar o afeto desagradável relacionado a uma representação. Ora, a esse processo de negação, altamente elaborado, segue-se a abordagem de outros dois tipos de negação no texto freudiano: "a negação do juízo atributivo e a negação do juízo de existência [que se situariam, dessa maneira, anteriormente], para-aquém da negação no momento em que ela aparece em sua função simbólica" (Hyppolite, 1954/1998, p. 898).

É esta primeira forma de negação (dos juízos), portanto, que Lacan irá utilizar para referenciar a simbolização e o mecanismo da Bejahung. Tal como a negação simbólica, trata-se igualmente de uma separação entre afeto e representação, porém, incidindo de forma imediata na apreensão da realidade, independente de as condições para o recalque serem instauradas. Ou seja, não haveria aqui uma suspensão do recalque, mas algo precisa ser colocado em suspenso, em dúvida, em xeque, para que uma outra coisa, que comprove ou não tal conteúdo, possa advir.

Antes de discutir o caso Dick, Lacan já havia abordado a Bejahung no caso freudiano do Homem dos Lobos. Freud (1918[1914]/2010) reconstrói a história da neurose infantil desse paciente adulto a partir de seu sonho com lobos, que representariam a forma como ele possivelmente havia presenciado a relação sexual de seus pais (a tergo), mostrando como tal criança negava a existência da diferença anatômica dos sexos, atribuindo ao ânus a função do coito. Nesse paciente, evidencia-se, assim, que a Bejahung do plano genital não se produziu, uma vez que não há traço desse plano no registro simbólico, mas apenas no registro de uma pequena alucinação: "a castração, que é precisamente o que para ele não existiu, manifesta-se sob a forma do que ele imagina - ter-se cortado o dedinho, tão profundamente que só se segura por um pedacinho de pele" (Lacan, 1953$54 / 1979$, p. 73). Neste momento, o sujeito não consegue falar sobre isso com ninguém: "é como se essa pessoa à qual ele imediatamente refere todas as suas emoções estivesse anulada. O outro não existe mais" (Lacan, 1953-54/1979, p. 74). Neste momento também:

O sujeito não é de modo algum psicótico. Só tem uma alucinação. Poderá ser psicótico mais tarde, não o é no momento em que tem essa vivência absolutamente limitada, nodal, estranha à vivência de sua infância, inteiramente desintegrada. Nesse momento da sua infância, nada permite classificá-lo como um esquizofrênico, mas trata-se de um fenômeno de psicose. (Lacan, 1953-54/1979, p. 74)

Lacan (1953-54/1979) nomeia essa não-Bejahung de Verwerfung, pois "não podemos colocá-la, absolutamente, no mesmo nível do que uma [de]negação" (p. 73). A Verwerfung se opõe à Bejahung primária e constitui como tal aquilo que é expulso:

A Verwerfung, portanto, corta pela raiz qualquer manifestação da ordem simbólica, isto é, da Bejahung que Freud enuncia como o processo primário em que o juízo atributivo se enraíza, e que não é outra coisa senão a condição primordial para que, do real, alguma coisa venha se oferecer à revelação do ser, ou, para empregar a linguagem de Heidegger, seja deixado-ser. (Lacan, 1954/1998, p. 389)

Não podemos confundir a Verwerfung com a Ausstossung ou a Verneinung. A Ausstossung aus dem Ich, a expulsão para fora do eu, constitui o real, na medida em que ele é o domínio do que subsiste fora da simbolização. Trata-se de um processo fundante do psiquismo, comum a todos os seres humanos. A negação [Verneinung], que sucede a expulsão [Ausstossung], é condição para a Bejahung, porém, tal afirmação [do símbolo] pode ser impedida pela forclusão [Verwerfung].

A negação [Verneinung] é igualmente um processo fundante do psiquismo, que pode ser encontrada em todas as estruturas clínicas, inclusive no negativismo dos psicóticos. Na negação, podemos identificar na separação entre representação e afeto uma "espécie de interseção do simbólico e do real, que podemos dizer imediata, na medida em que ela opera sem intermediário do imaginário, mas que se mediatiza, ainda que precisamente sob uma forma que se renega, pelo que foi excluído no primeiro tempo da simbolização" (Lacan, 1954/1998, p. 385).

Hyppolite (1954/1998) indica o que pode ser esse conteúdo excluído, expulso [Ausstossung], ao dizer que "o que desaparece nesse prazer de negar são os componentes libidinais" (p. 900).

Assim, o que pode ser introjetado, no final das contas, é o conteúdo intelectual, o simbólico, já apartado de toda afetividade. Freud (1925/2007) mesmo ressalta que "o trabalho de emitir juízos só se torna possível graças [...] a criação do símbolo da negação [Verneinungssymbol]" (p. 150 - grifos nossos) -, de modo que é também pela negação que se torna possível, para Hyppolite (1954/1998), uma "atitude fundamental de simbolicidade explícita" (p. 901). Podemos concluir, com Hyppolite, que o que é bom e eu quero comer é o simbólico; enquanto o que é mau, eu quero cuspir e expulsar é a pulsão. Após esse julgamento de atribuição, o 
juízo de existência seria possível pelo símbolo da negação, que operaria não apenas a separação dos componentes afetivos e intelectuais, como também a diferenciação entre o eu e o objeto externo, a partir da nomeação, possibilitada pela Bejahung [afirmação]. Desse modo, mesmo que a princípio o eu se confunda com os objetos que lhe trazem satisfação, o simbólico (através da Bejahung) não permitirá que essa equivalência imaginária ultrapasse certos limites que poderiam, inclusive, abalar as fronteiras do próprio eu.

Voltando ao caso do Homem dos Lobos, o conteúdo da alucinação, tão maciçamente simbólico, deve seu aparecimento no real justamente ao fato de nunca ter existido para o sujeito (Lacan, 1954/1998, p. 394). Aquilo que não foi deixado ser na Bejahung, o que o sujeito suprimiu (verworfen) da abertura para o ser, não será reencontrado em sua história, se considerarmos esta como o lugar onde o recalcado vem a reaparecer. No recalque, sabe-se daquilo que não se quer saber, mas tal paciente simplesmente "não quis saber dela (da castração)" (Freud, 1918[1914]/2010, p. 114). Para Lacan (1955-56/2008, p. 177), se há coisas de que o paciente não quer nada saber, isso supõe outro mecanismo. O recalque depende de uma simbolização primordial e $o$ que não veio à luz do simbólico reaparece no real (p. 390). Enfim, tudo o que é recusado na ordem simbólica, no sentido da forclusão, reaparece no real.

Na leitura de Lacan, vemos o esboço da diferenciação das estruturas clínicas, já pelo processo da negação, o que não quer dizer que, quando criança, o Homem dos Lobos fosse um psicótico, como já mencionamos. A questão do diagnóstico deste paciente é, ainda hoje, discutida por psicanalistas, até mesmo pelo fato de Freud usar o termo neurose infantil para um paciente adulto. Seria mesmo um neurótico que o psicanalista recebeu em seu consultório?

Hyppolite (1954/1998) afirma que "É preciso ver na [de] negação uma atitude concreta na origem do símbolo explícito da negação, símbolo explícito este que é o único a possibilitar o que quer que seja como utilização do inconsciente, enquanto mantém o recalque" (p. 901). Pois bem, se o neurótico pode se servir de seu inconsciente, para o pensamento e para as sublimações, o psicótico se depara com ele na realidade. A atitude de negação que Freud aborda em seu texto como a suspensão [Aufhebung] do recalque seria possível apenas nos casos em que o recalque pode se efetivar - isto é, no âmbito das neuroses. Do outro lado, teríamos o negativismo.

Lacan (1953-54/1979) quer que retenhamos do comentário de Hyppolite "a diferença de nível entre o simbólico como tal, a possibilidade simbólica, a abertura do homem aos símbolos, e, por outro lado, a sua cristalização no discurso organizado enquanto contém, fundamentalmente, a contradição" (p. 76). Para entendermos melhor esses diferentes níveis em que o simbólico pode se apresentar, bem como visando uma melhor apreensão dos mecanismos de Ausstossung, Verneinung e Bejahung na constituição psíquica, vejamos, a seguir, o caso Dick.

\section{O Caso Dick, por Melanie Klein}

O caso Dick se refere ao atendimento psicanalítico de um menino de quatro anos de idade, indiferente à presença das pessoas - mesmo as mais próximas. Ele não demonstrava nenhum afeto ou interesse, quase não brincava e Klein (1930/1996, p. 253-254) nota que sua ansiedade era pequena quando comparada a de outras crianças. Nas palavras da psicanalista:

[Dick] limitava-se a juntar alguns sons de forma desconcatenada e repetia constantemente determinados ruídos. Quando falava, geralmente empregava seu paupérrimo vocabulário de forma incorreta. Não se tratava apenas de uma incapacidade de se fazer entender: na verdade, não tinha a menor vontade de fazer isso. Mais ainda, a mãe de Dick às vezes conseguia sentir no menino uma forte atitude negativa que se expressava no fato de frequentemente fazer o oposto daquilo que se esperava dele. (Klein, 1930/1996, p. 253 - itálicos da autora)

Ainda com relação à linguagem, era possível observar que Dick alterava palavras que, em outras ocasiões, pronunciava corretamente, bem como repetia mecanicamente algumas palavras até que todos à sua volta não aguentassem mais. $\mathrm{O}$ menino era insensível à dor, não manifestando o desejo de ser reconfortado nestas situações. Sua inabilidade física era explícita, apesar de manejar bem a colher que usava para comer. Para Klein (1930/1996, p. 254), não havia dúvidas de que os comportamentos de Dick diferiam sobremaneira daqueles de crianças neuróticas.

Dessa forma, Melanie Klein (1930/1996) oferece como explicação teórica para o quadro clínico de Dick o fracasso nas etapas iniciais de seu desenvolvimento. Etapas estas dominadas pelo sadismo, que se tornaria ativo em todas as fontes do prazer libidinal. Logo no início, teríamos o desejo sádico-oral de devorar o seio da mãe (ou a própria mãe), de modo que o principal objetivo do indivíduo seria o de se apossar do conteúdo do corpo da mãe e destruí-la com todas as armas ao alcance do sadismo (cf. Klein, 1930/1996, p. 251 - grifos nossos). É válido ressaltar que o corpo da mãe abriga vários conteúdos: o pênis do pai (incorporado à mãe durante o ato sexual), os excrementos, outras crianças etc. todos eles comestíveis. Klein (1930/1996) não questiona a origem dessas fantasias das crianças - para ela, é quase um dado biológico -, mas, de nosso lado, podemos entender essa mãe como a personificação de tudo aquilo que existe no mundo externo. É a mãe esse primeiro outro mais próximo com quem o sujeito tem que lidar.

De acordo com Klein (1930/1996, p. 252), tal sadismo que, veremos, pode equivaler à descarga das excitações, dos afetos, enfim, à pulsão - mobiliza uma defesa do ego anterior ao recalque (que seria um mecanismo mais elaborado). Tal defesa implica, portanto, a expulsão [Ausstossung] do sadismo e a destruição do objeto:

O sadismo se torna uma fonte de perigo, não só porque oferece uma oportunidade para a liberação de ansiedade, mas também porque o sujeito acredita que as armas empregadas para destruir o objeto também se voltam contra si mesmo. O objeto do ataque se torna uma fonte de perigo porque o sujeito teme sofrer dele ataques semelhantes como retaliação. (Klein, 1930/1996, p. 252)

Nesse ponto de sua argumentação, Melanie Klein (1930/1996) faz apelo a duas referências muito pertinentes: (a) Ferenczi (1873-1933), que acredita que a identificação, precursora do simbolismo, surge da tentativa do bebê de reencontrar em todo objeto os seus próprios órgãos e seu funcionamento; e (b) Jones (1879-1958), que mostra que 
o princípio de prazer torna possível que duas coisas bem diferentes sejam igualadas, por causa de uma similaridade calcada no prazer ou no interesse. A partir daí, Klein (1930/1996) conclui que é através da igualdade simbólica que as coisas, as atividades e os interesses se tornam o conteúdo de fantasias libidinais. Ora, devemos apenas atentar para o caráter imaginário dessa igualdade simbólica, na medida em que todo o processo de constituição do objeto perigoso ocorre como um reflexo das tendências do próprio sujeito, como se isso se desse em espelho. Desde o Projeto, Freud (1895/1995) já aponta para essa possibilidade de associação entre dois objetos a partir das sensações de prazer. Cabe, em seguida, mostrar como tal associação será possibilitada pelo simbolismo, advindo da negação e da consequente destruição do objeto.

A psicanalista inglesa aponta para o fato de que o desejo de conhecimento surge na mesma época que o sadismo e se concentra no corpo da mãe. As fantasias sádicas dirigidas contra o interior desse corpo constituem a primeira e mais básica relação com o mundo externo e a realidade. O grau de sucesso com que o indivíduo consegue passar por essa fase vai determinar até que ponto ele poderá ter acesso a um mundo externo que corresponda à realidade (cf. Klein, 1930/1996, p. 252-253). Continuando com a ideia de que a mãe está no lugar de tudo aquilo que se refere à realidade, a dimensão da fantasia não nos interessa tanto quanto o desejo de conhecimento, que podemos remeter à origem do pensamento. O pensamento, por sua vez, deve nos levar à questão do simbolismo, tal como no texto freudiano sobre a negação, ajudando-nos a refletir sobre o que estaria na base da relação do indivíduo com o mundo externo e com a realidade em geral.

Nesse sentido, o problema de Dick está na falta de relação com a realidade devido a uma imobilidade na formação de símbolos, que teria relação com o desenvolvimento do eu. Aliás, é Klein (1930/1996) quem ressalta que o único interesse de Dick por objetos se restringia aos trens e estações, assim como às maçanetas e portas, e na maneira como estas se abriam e fechavam (p. 256). Para ela, tais objetos e ações estavam ligados à penetração do pênis no corpo da mãe, de modo que, na sua interpretação, o que imobilizava a formação de símbolos em Dick era o medo do que lhe seria feito (principalmente pelo pênis do pai) caso penetrasse no corpo da mãe. Vemos que Klein supõe um alto grau de interpretação da realidade por parte do garoto, apesar de reconhecer o seu desligamento em relação à mesma.

Dessa imobilidade decorre a falta de agressividade em Dick e, por conseguinte, seus impulsos sádicos não podiam ser dirigidos contra o corpo da mãe, o que resultou na suspensão das fantasias e na interrupção da formação de símbolos, comprometendo todo o desenvolvimento posterior da criança (cf. Klein, 1930/1996, p. 256).

Pode-se verificar que Melanie Klein coloca, de um lado, um excesso de fantasia ligado ao conteúdo do corpo da mãe e ao que este pode oferecer de perigo; e, de outro, uma falta de fantasia na relação com os objetos. Tendemos a pensar que não havia fantasia tout court e que a falta de agressividade ou sadismo se devia a um problema na defesa do eu (uma inibição no mecanismo da expulsão [Ausstossung]) - e não era decorrente de nenhuma fantasia -, mas deixemos essas discussões para depois. Por ora, gostaríamos de enfatizar a astúcia clínica da psicanalista que, ao notar a pobreza de representações na criança - não havia relação afetiva ou simbólica de Dick com os objetos, suas ações diante deles não eram tingidas pela fantasia e, por isso, não era possível atribuir-lhes o caráter de representações simbólicas - realiza uma mudança em sua técnica, fazendo interpretações bastante precoces (cf. Klein, 1930/1996, p. 260). Vejamos.

Na primeira sessão, Klein pega o trem grande, coloca ao lado de outro menor e diz: "Trem-Papai" e "Trem-Dick". O menino pega o "Trem-Dick", empurra-o até a janela e diz: "Estação". Klein lhe explica: "A estação é a mamãe; o Dick está entrando na mamãe". Dick larga o trem, corre para o espaço entre as portas, diz "escuro" e sai correndo. Ele repete esse movimento diversas vezes até que Klein lhe explica: "É escuro dentro da mamãe. O Dick está dentro da mamãe escura". A partir daí, Dick diz duas vezes, num tom questionador: "Babá?”. E Klein responde: "A babá já vem" - frase que ele repetiu desde então, empregando as palavras de forma correta (cf. Klein, 1930/1996, p. 257).

Antecipemos, neste ponto, uma pequena observação de Lacan (1953-54/1979, p. 102 e p. 105) quanto ao fato de a criança verbalizar um primeiro apelo - Dick pergunta pela babá. O apelo, até então inexistente no menino, é também a possibilidade da recusa, pois o outro pode não responder. É, pois, no momento em que se produz o apelo que se estabelecem no sujeito as relações de dependência - como Klein não deixará de notar. Lacan (1953-54/1979, p. 102) vê, ainda no apelo, uma primeira comunicação, no sentido próprio, técnico, do termo.

Fechado esse pequeno parênteses, retornando ao caso Dick, nas demais consultas, ele não parava de repetir: “A babá vem?". Tem uma crise de ansiedade, chama por Klein e pela babá e, ao final da sessão, recebe a última com uma alegria fora do comum. A partir de então, começa a chorar sempre que a babá vai embora. Klein (1930/1996, p. 257) faz uma correlação entre o surgimento da ansiedade e a dependência do outro, de modo que quando ela diz: “A babá já vem”, Dick se sente reconfortado. A psicanalista nota um princípio de curiosidade da criança pelos brinquedos.

À medida que seus interesses iam aumentando, o menino expandia seu vocabulário, pois sua curiosidade abrangia também o nome das coisas. As palavras que antes ouvia e ignorava, Dick agora lembrava e empregava corretamente. Pois bem, juntamente com o desenvolvimento de seus interesses vêm à tona as relações de objeto, que, até então, estavam ausentes. Isso é visível em sua vontade de se comunicar e quando sente falta da presença das outras pessoas. Klein (1930/1996, p. 260) afirma que há indícios de que Dick esteja começando a estabelecer certa relação com a realidade.

Seis meses depois do início do tratamento, o prognóstico de Dick é favorável. Melanie Klein (1930/1996, p. 261) não atribui os avanços no desenvolvimento da criança a nenhuma influência educacional, mas, sim, às suas interpretações. Estas, mesmo que baseadas em seu próprio conhecimento uma vez que as representações de Dick eram relativamente vagas -, permitiram o acesso ao inconsciente da criança e conseguiram ativar a ansiedade e outros afetos (cf. Klein, 1930/1996, p. 260). Veremos o que Lacan tem a dizer sobre 
isso, porém, antes de iniciarmos uma nova discussão, cabe destacar um último ponto que nos interessa nas concepções de Melanie Klein.

A psicanalista demarca incessantemente as diferenças do quadro psicopatológico de Dick com relação às manifestações neuróticas que ela já pôde observar em inúmeras crianças. Ela nos conta que o Dr. Forsyth, diagnosticou no menino uma demência precoce (esquizofrenia), semelhante a que podemos encontrar nos adultos. O psiquiatra não encontrou qualquer alteração orgânica relacionada ao quadro de Dick e a ausência deste fator pôde ser comprovada pela influência do tratamento psicológico sobre o caso. Assim, de um lado, Klein $(1930 / 1996$, p. 262) tinha a certeza de que não se tratava de uma psiconeurose; e, de outro, questionava o diagnóstico de psicose, na medida em que ela não verificava uma regressão no desenvolvimento de Dick, mas, sim, uma inibição. Ela não se aprofunda nessa discussão e opta por defender que a esquizofrenia é mais comum na infância do que supomos normalmente. Seu diagnóstico é raro, pois os pais raramente procuram os psiquiatras, uma vez que seus sintomas se confundem com aspectos naturais do desenvolvimento infantil: afastamento da realidade, incapacidade de se concentrar, fala sem sentido, fantasmas, medos, dentre outros. Enfim, de acordo com Klein (1930/1999, p. 264), a esquizofrenia se situaria na fase do sadismo oral em que predomina a defesa contra os impulsos destrutivos: expulsão [Ausstossung] do sadismo e destruição do objeto, sem possibilidades de Bejahung e simbolização.

\section{O Caso Dick, por Lacan}

Em seus comentários sobre o caso Dick, Lacan (195354/1979) exclama: "Melanie Klein enfia o simbolismo, com a maior brutalidade, no pequeno Dick!" (p. 83). Ela joga em cima dele uma interpretação "brutal do mito edípico, quase tão revoltante para nós quanto para qualquer leitor -Você é $o$ trenzinho, você quer foder a sua mãe" (p. 84). O psicanalista reconhece que esse modo de trabalhar na clínica não pode ser dissociado do diagnóstico do caso - e vimos que é nessa via que a própria Melanie Klein justifica seu método de interpretação precoce - e lança a seguinte observação: "mas é certo que depois dessa intervenção, alguma coisa se produz" (p. 84).

Além do tema do apelo, abordado no tópico anterior, Lacan (1953-54/1979, p. 102-103) nota que, após Klein situar o "Trem-Papai" e o "Trem-Dick", a criança se põe a brincar com o seu trenzinho e diz a palavra estação. Para ele, esse é um momento crucial, em que se esboça a junção da linguagem e do imaginário do sujeito. E Klein continua: - $A$ estação é Mamãe. Dick entrar na mamãe - o que faz com que, a partir daí, tudo se desencadeie, pois a criança progride muito depressa.

De acordo com a leitura lacaniana, Klein introduziu a verbalização em Dick, simbolizando, através do mito edipiano, uma relação efetiva de um ser, nomeado, com um outro. Quando ela lhe entrega o esquema do Édipo, a relação imaginária em que vive o sujeito, embora extremamente pobre, já é suficientemente complexa para que se possa dizer que ele tem o seu próprio mundo. Mas este mundo, constituído do real primitivo, é inefável, não pode nos dizer nada, não temos nenhum meio de penetrar nele, senão por extrapolações simbólicas, como as que vemos no sistema kleiniano, quando ela nos diz, por exemplo, que no interior do império do corpo materno estão outras crianças, o pênis do pai etc. (cf. Lacan, 1953-54/1979, p. 104).

O que importa para Lacan (1953-54/1979, p. 105) é apreender como esse mundo infantil se põe em movimento; como imaginário e real começam a se estruturar; como se desenvolvem os investimentos sucessivos que delimitam a variedade dos objetos humanos, que são nomeáveis. Grosso modo, todo esse processo parte de uma palavra significativa, que humaniza o homem, e é isso que Melanie Klein pôde fornecer a Dick.

Lacan (1953-54/1979, p. 98) destaca que Dick tem um vocabulário limitado e, muitas vezes, incorreto. Ele deforma as palavras, as emprega mal, enquanto em outros momentos parece conhecer seus sentidos. Melanie Klein insiste no fato de que essa criança não tem o desejo de se fazer compreender, não procura se comunicar, e as suas únicas atividades mais ou menos lúdicas são emitir sons sem significação e comprazerse com eles. Dick possui, mesmo assim, alguma coisa da linguagem, dispõe de certos elementos do aparelho simbólico e, em relação a esse sistema de linguagem:

A prova é que brinca com ele. Serve-se dela para fazer um jogo de oposição contra as tentativas de intrusão dos adultos.

Por exemplo, comporta-se de uma forma que é dita no texto negativista. Quando sua mãe lhe propõe um nome, que é capaz de produzir de maneira correta, o reproduz de maneira ininteligível, deformada, que não pode servir para nada. Reencontramos aqui a distinção entre negativismo e denegação [atitude de negação] - como nos lembrou o Sr. Hyppolite, provando por aí não somente sua cultura, mas que já viu doentes. Dick serve-se da linguagem de uma forma propriamente negativista. (Lacan, 1953-54/1979, p. 101)

O sistema pelo qual Dick vem se situar na linguagem é interrompido, ao nível da fala. Lacan (1953-54/1979, p. 102) nos lembra que a linguagem não é a mesma coisa que a fala. Dick é, até certo nível, mestre da linguagem, mas ele não fala. É um sujeito que está aí e que, literalmente, não responde. A palavra não chegou a ele, pois a linguagem não envolveu o seu sistema imaginário, cujo registro é excessivamente curto - trens, portas, lugar negro. Suas faculdades, não de comunicação, mas de expressão, estão limitadas a isso. Para ele, o real e o imaginário são equivalentes. Isso porque, como podemos depreender da citação acima, Dick não fez a Bejahung, ele não fez a assunção da palavra, do significante que permitiria a simbolização da realidade: "[Dick] tem uma certa apreensão dos vocábulos, mas desses vocábulos não fez a Bejahung - não os assume" (Lacan, 1953-54/1979, p. 86). Em seu Seminário 3, Lacan (1955-56/2008, p. 21) afirma ser preciso admitir, atrás do processo de verbalização, uma Bejahung primordial, uma admissão no sentido do simbólico. No caso de Dick, no plano da negação (Verneinung), ele permanece no nível do negativismo, sem atingir a atitude de negação simbólica.

Lacan (1953-54/1979) nota que Dick está inteirinho na realidade, no estado puro, inconstituído: "Ele está inteirinho no indiferenciado" (p. 84). A realidade assume um caráter uniforme para Dick: "tudo lhe é igualmente real, igualmente 
indiferente” (p. 98), pois ele é incapaz de simbolizá-la. "Todo o problema a partir de então é o da junção do simbólico e do imaginário na constituição do real" (p. 90).

O caso Dick, para Lacan (1953-54/1979, p. 89), evidencia o jogo recíproco dos três grandes sistemas de referência real, simbólico e imaginário -, sem os quais não é possível compreender a técnica e a experiência freudianas. $\mathrm{O}$ psicanalista afirma que:

Supomos na origem todos os issos, objetos, instintos, desejos, tendências etc. É, pois, a pura e simples realidade que não se delimita em nada, que não pode ser ainda objeto de nenhuma definição, que não é nem boa, nem má, mas ao mesmo tempo caótica e absoluta, original. É o nível ao qual Freud se refere em Die Verneinung, quando fala, dos julgamentos de existência - ou bem é, ou bem não é. E é aí que a imagem do corpo dá ao sujeito a primeira forma que lhe permite situar o que é e o que não é do eu. (Lacan, 1953-54/1979, p. 96)

Pois bem, a realidade está dada a princípio e tudo aquilo que supomos na origem são tentativas de se aproximar e tentar compreender este real inefável, muitas vezes, pela via do imaginário. Lacan (1953-54/1979, p. 99) não descarta a ideia de que ao longo do processo das suas relações instintivas com esse objeto privilegiado que é a mãe, a criança também proceda a uma série de relações de incorporações imaginárias: pode morder, absorver o corpo de sua mãe e, dessa forma, destruí-lo. Nesse corpo materno, a criança espera encontrar certo número de objetos, mas estes objetos podem ser perigosos para ela exatamente pela mesma razão que ela é perigosa para eles: "Em espelho, é o caso de dizê-lo, ela os reveste das mesmas capacidades de destruição das quais ela própria se sente portadora" (Lacan, 1953-54/1979, p. 99). Essa relação especular está na base da formação da imagem corporal e, como vimos, trata-se de algo que depende fundamentalmente do registro imaginário. Porém, este imaginário depende do simbólico.

Lacan (1953-54/1979) afirma que esses objetos perigosos serão certamente exteriorizados, "isolados desse primeiro continente universal, desse primeiro grande todo que é a imagem fantasiada do corpo da mãe, império total da primeira realidade infantil" (p. 99). Porém, aparecerão sempre providos do mesmo acento maléfico que terá marcado suas primeiras relações com eles. É evidente que o psicanalista está seguindo o raciocínio kleiniano. Contudo, de acordo com a sua própria teoria, o caráter maléfico destes objetos externos está ligado ao seu conteúdo afetivo e pulsional, expulso através do mecanismo da Ausstossung. A seguir, com a negação e a afirmação do símbolo será possível que a criança reintrojete esse objeto e possa dirigir seus interesses para outros objetos menos perigosos.

Neste ponto de sua argumentação, Lacan (1953-54/1979) nos explica que a introjeção não é simplesmente o contrário da projeção, mas trata-se de uma introjeção simbólica: "A introjeção é sempre introjeção da palavra do outro, o que introduz uma dimensão muito diferente da de projeção" (p. 100). Ou seja, se aquilo que pode ser expulso, exteriorizado, encontra uma referência no campo afetivo e pulsional, o que será introjetado ou afirmado (Bejahung) é da ordem do simbólico. E, entre esses dois registros, temos o imaginário procedendo ao seu jogo de equivalências, calcado sob o princípio de prazer (já que a regulação instintual deixa de ser operativa no ser humano). Por conseguinte, diferentes objetos do mundo exterior, mais neutralizados, serão colocados como os equivalentes dos primeiros, ligando-se a eles por uma equação imaginária (por exemplo, fezes - urina). "Assim, a equação simbólica que redescobrimos entre esses objetos surge de um mecanismo alternativo de expulsão e de introjeção, de projeção e de absorção, quer dizer, de um jogo imaginário" (Lacan, 1953-54/1979, p. 99 - grifos nossos). Enfim:

Normalmente é pelas possibilidades de jogo da transposição imaginária que se pode fazer a valorização progressiva dos objetos, no plano que se chama comumente afetivo, por uma multiplicação, um desdobramento em leque de todas as equações imaginárias que permitem ao ser humano ser o único entre os animais a ter um número quase infinito de objetos à sua disposição - de objetos marcados por um valor de Gestalt no seu Umwelt, de objetos isolados nas suas formas. Melanie Klein sublinha a pobreza do mundo imaginário, e, no mesmo lance, a impossibilidade para essa criança [Dick] de entrar numa relação afetiva com os objetos enquanto estruturas. Correlação que é importante apreender. (Lacan, 1953-54/1979, p. 100-101)

Podemos ver em Dick um esboço de imaginificação do mundo exterior, pronta a aflorar, quando ele consegue, por exemplo, entificar no trem ele e seu pai (Lacan, 195354/1979, p. 99). Mesmo assim, o número de objetos que são significativos para ele é extremamente reduzido.

Lacan (1953-54/1979, p. 84) defende que o que constitui um mundo humano é o interesse pelos objetos. O mundo humano, como vimos na citação acima, é um mundo infinito quanto aos objetos e, poderíamos nos perguntar se "a esse respeito, Dick vive num mundo não humano" (p. 84)?

Lembremos, com o auxílio de Lacan (1953-54/1979), que, na explicação de Melanie Klein, no mundo humano os objetos se multiplicam e se desenvolvem graças a um processo de expulsão ligado ao instinto de destruição primitivo. Essa seria uma relação primitiva, e mesmo instintiva, do ser. À medida que se produzem as expulsões para fora do mundo primitivo do sujeito, que não está ainda organizado no registro da realidade humana, comunicável, surge cada vez um novo tipo de identificação, acompanhada de ansiedade: a cada uma das relações objetais corresponde, dessa forma, um modo de identificação cujo sinal é a ansiedade. Ansiedade esta, lembremos, ligada à projeção das próprias intenções sádicas no objeto. Normalmente, o sujeito atribui a esses objetos da sua identificação primitiva uma série de equivalências imaginárias que multiplicam o seu mundo - esboça identificação com certos objetos, retiraos, os refaz com outros. Mas Dick conta com um número muito limitado de objetos, que não pode nem mesmo nomear. Lacan (1953-54/1979) aventa a hipótese de que em Dick há a simbolização antecipada de uma única identificação primária com o vazio, o preto - o intervalo entre as portas.

Pois bem, Dick não pôde nem mesmo chegar à primeira espécie de identificação, as identificações com os objetos que precedem a identificação egoica/eu-óica, que seriam um esboço de simbolismo. Ainda assim, essa identificação com o nada é o que é humano na estrutura do sujeito, e é o que nele responde. Respondendo à questão que ele mesmo havia colocado, Lacan (1953-54/1979) afirma que não se trata, de forma alguma, de uma realidade absolutamente 
desumanizada: "Ela significa, ao seu nível. Ela já está simbolizada porque se lhe pode dar um sentido" (cf. Lacan, 1953-54/1979, p. 84-85).

É o que Melanie Klein faz. A psicanalista fala com Dick mesmo que ele ignore sua presença. Ela dá nomes ao que participa do símbolo porque pode ser imediatamente nomeado, mas que, para esse sujeito, só era, até então, realidade pura e simples (cf. Lacan, 1953-54/1979, p. 85). Dick é capaz de simbolizar a realidade a sua volta a partir desse núcleo, "dessa pequena célula palpitante de simbolismo que lhe deu Melanie Klein. É o que se chama em seguida - ter aberto as portas do seu inconsciente" (Lacan, 195354/1979, p. 103).

Desse modo, se Melanie Klein acredita ter conseguido o acesso ao inconsciente de Dick com suas interpretações, Lacan (1953-54/1979) vai além ao afirmar que o que ela fez foi fundar o inconsciente de Dick: "o inconsciente é $O$ discurso do outro" (p. 103). Até este momento, não havia nenhuma espécie de inconsciente no sujeito. É o discurso de Klein que enxerta sobre a inércia egóica inicial da criança as primeiras simbolizações da situação edipiana. No caso de Dick, as simbolizações determinam uma posição inicial a partir da qual o sujeito pode fazer agir o imaginário e o real e conquistar seu desenvolvimento. É a partir daí que surge o seu interesse pelos objetos e pelo mundo. Nas palavras de Lacan (1953-54/1979):

na relação do imaginário e do real, e na constituição do mundo tal como ela resulta disso, tudo depende da situação do sujeito. E a situação do sujeito - vocês devem sabê-lo desde que thes repito - é essencialmente caracterizada pelo seu lugar no mundo simbólico ou, em outros termos, no mundo da palavra. É desse lugar que depende o fato de que tenha direito ou defesa de se chamar Pedro [ou Dick]. (Lacan, 1953-54/1979, p. 97)

O desenvolvimento só ocorre na medida em que o sujeito se integra ao sistema simbólico, aí se exercita, aí se afirma pelo exercício de uma palavra verdadeira. E essa palavra pode vir de qualquer pessoa - no caso de Dick, ela veio de Melanie Klein. O que importa ressaltar é que o mundo exterior - o mundo real, humanizado, simbolizado - só pode se constituir quando são produzidos, no bom lugar, uma série de encontros (cf. Lacan, 1953-54/2007, p. 105). Para finalizarmos este subitem, mais um comentário de Lacan (1953-54/1979) sobre este caso:

A partir do caso Dick e utilizando as categorias do real, do simbólico e do imaginário, mostrei-lhes que pode acontecer que um sujeito que dispõe de todos os elementos da linguagem, e que tem a possibilidade de fazer certo número de deslocamentos imaginários que lhe permitem estruturar o seu mundo, não esteja no real. Por que não está? - unicamente porque as coisas não vieram numa certa ordem. (p. 105)

\section{Considerações Finais}

Apesar de todas as controvérsias que podem ser suscitadas pelo método kleiniano, Lacan destaca que alguma coisa se produz na análise de Dick a partir unicamente da fala. Essa fala funda o inconsciente de Dick, na medida em que é capaz de situá-lo na linguagem, no simbólico, como outro que não ele mesmo. Ao chamar o trem de Dick e interpretar a "brincadeira" do menino de acordo com o mito edipiano, Klein supõe que ali está um sujeito que tem seus próprios desejos - e que, pelos efeitos de sua interpretação, não se restringem a "foder" sua mãe. O fato é que Klein não se limita a nomear as coisas para a criança ou a descrever seu comportamento; ela o concebe a partir de um outro lugar. Esse método se estende a outras "brincadeiras" e vemos que, em todas elas, Klein acaba por localizar a criança no romance familiar. O que ela faz, igualmente, é atribuir uma certa historicidade ao mundo de Dick. A criança se interessa por esse novo mundo povoado de fantasias e, desde então, os objetos ganham outro colorido e se tornam mais atrativos.

$\mathrm{O}$ caso Dick também tem muito a nos ensinar a respeito do simbolismo. Em seu seminário sobre as psicoses, Lacan (1955-56/2008) afirma que na relação do sujeito com o símbolo, há a possibilidade de uma Verwerfung primitiva, ou seja, a Bejahung pode realizar-se ou não, de modo que alguma coisa pode não ser simbolizada, que vai se manifestar no real. $\mathrm{O}$ que é submetido à Bejahung, à simbolização primitiva, tem destinos diversos do que aquilo que cai sob o golpe da Verwerfung: "há, portanto, na origem, Bejahung, isto é, afirmação do que é, ou Verwerfung" (Lacan, 1955-56/2008, p. 101). Se Dick não era capaz de fazer a Bejahung é porque alguma coisa se passou no nível da negação - o que pode ser comprovado por suas atitudes negativistas. Dessa maneira, pode-se compreender a Verneinung como um mecanismo de defesa que opera independentemente da Bejahung, fornecendo uma proteção contra o excesso de estimulação vindo do mundo externo. Lacan (1955-56/2008, p. 102) também aponta para o fato de que no interior da Bejahung acontecem todas as espécies de acidentes e nada nos indica que a supressão primitiva (Ausstossung) tenha sido produzida de maneira apropriada.

Ora, é precisamente no nível da expulsão do sadismo que Melanie Klein situa a inibição de Dick. O menino, incapaz de operar a destruição do objeto - pela palavra, que, na concepção de Lacan é o equivalente da morte da coisa - se encontra paralisado na sua atividade de formação de símbolos. De fato, a destruição do objeto no sistema kleiniano implica que tal objeto possa resistir para além das projeções imaginárias da criança, ou seja, em um universo simbólico e compartilhado. Nesse sentido, o trabalho da Verneinung fica comprometido, encontrando como única alternativa a negação da experiência que não pode ser simbolizada. Sem poder discernir entre o bom e o mau objeto, não há o que esperar da realidade. Trata-se, apenas, de proteger-se dela.

Com este trabalho pudemos mostrar como a metapsicologia freudiana pode nos ajudar a compreender a clínica psicanalítica, ainda que apoiados numa releitura lacaniana e numa observação clínica kleiniana. Os mecanismos de Ausstossung, Verneinung e Bejahung, tardiamente mobilizados por Freud, foram explícita ou implicitamente retomados por seus mais importantes seguidores para dar conta de um problema que continua a intrigar os psicanalistas: a constituição psíquica.

Dessa forma, ao trabalharmos com a hipótese de que, a princípio, no mundo caótico e irrepresentável do recémnascido (real inefável) opera o mecanismo de Ausstossung [expulsão], seguido da Verneinung [negação], que faria a 
separação do afetivo e do intelectual, já sob a influência do mundo simbólico que circunda a criança, teríamos, por fim, a Bejahung [afirmação], como assentimento a essa ordem simbólica que organizaria o mundo das pulsões. O problema é que essa sequência está em constante atividade na criança e nem sempre as coisas se passam em certa ordem. Há sempre falhas, pedaços de real não simbolizados, excessos de descargas pulsionais, que serão absorvidas pelo corpo (psicossomática), e o imaginário, que opera para além do que é dito, também pela via corporal, singularizando as vivências de cada sujeito.

Assim, voltando ao caso Dick e às suas dificuldades de simbolização [Bejahung] e inibição da expulsão [Ausstossung], nos perguntamos se já poderíamos falar aqui de forclusão [Verwerfung]? E, se supormos que sim, essa forclusão já determinaria uma estrutura clínica psicótica ou, tal como nos alerta Lacan, quando aborda a alucinação do dedo cortado no Homem dos Lobos, não podemos ainda falar de psicose na criança, mas apenas de alguma coisa que não pode ser simbolizada nesse momento? Essa ausência de simbolização, que tem como consequência atitudes negativistas, ao ser compreendida no escopo da Verneinung, permite um prognóstico mais otimista para alguns quadros clínicos da infância, sob o ponto de vista da psicanálise. No seminário do ano seguinte, Lacan (1954-55/1985) assevera que "o diagnóstico de psicose na criança é discutido e discutível” (p. 134) e questiona se seria adequado empregar a mesma palavra para as psicoses na criança e no adulto, uma vez que "a psicose não é estrutural, de jeito nenhum, da mesma maneira na criança e no adulto" (p. 135). Além do tema da psicose, há também a pergunta sobre o caso Dick ser um quadro de autismo (inibição, ao invés de regressão) e em que esse diagnóstico poderia nos auxiliar na direção do tratamento. Essas são questões que aguardam respostas e merecem outras investigações.

\section{Referências}

Freud, S. (1995). Projeto de uma psicologia (O. Gabbi Jr., trad.). Rio de Janeiro: Imago. (Trabalho original publicado em 1895)

Freud, S. (2007). A Negativa. In S. Freud, Escritos sobre a psicologia do inconsciente (vol. 3., L. Hanns, trad., pp. 145157). Rio de Janeiro: Imago. (Trabalho original publicado em 1925)

Freud, S. (2010). História de uma neurose infantil (“O Homem dos Lobos”). In S. Freud, Obras completas (vol. 14., P. C. Souza, trad., pp. 13-160). Rio de Janeiro: Imago. (Trabalho original publicado em 1918[1914])

Hyppolite, J. (1998). Comentário falado sobre a "Verneinung" de Freud. In J. Lacan, Escritos (pp. 893-902). Rio de Janeiro: Jorge Zahar. (Trabalho original publicado em 1954)

Klein, M. (1996). A importância da formação de símbolos no desenvolvimento do ego. In M. Klein, Amor, culpa e reparação (pp. 249-264). Rio de Janeiro: Imago. (Trabalho original publicado em 1930)

Lacan, J. (1979). O Seminário, livro 1: Os escritos técnicos de Freud. Rio de Janeiro: Zahar. (Trabalho original proferido em 1953-54)
Lacan, J. (1985). O Seminário, livro 2: O eu na teoria de Freud e na técnica da psicanálise. Rio de Janeiro: Jorge Zahar. (Trabalho original proferido em 1954-55)

Lacan, J. (1998). Introdução ao comentário de Jean Hyppolite sobre a Verneinug de Freud. In J. Lacan. Escritos (pp. 370-382). Rio de Janeiro: Jorge Zahar Editor. (Trabalho original publicado em 1954).

Lacan, J. (1998). Resposta ao comentário de Jean Hyppolite sobre a Verneinug de Freud. In J. Lacan, Escritos (pp. 383-401). Rio de Janeiro: Jorge Zahar Editor. (Trabalho original publicado em 1954)

Lacan, J. (2008). O Seminário, livro 3: As psicoses. Rio de Janeiro: Zahar. (Trabalho original proferido em 1954-55)

Recebido em 10.06.2014

Primeira decisão editorial em 12.03.2015

Versão final em 09.04.2015

Aceito em 17.04.2015 